\title{
Insects New Source of Allergens for Animals and Human
}

\author{
Kucharski M* \\ Maciej Kucharski veterinarian, Ministry of Agricultural Warsaw, Poland \\ *Corresponding author: Maciej Kucharski veterinarian, Ministry of Agricultural \\ Warsaw, Poland, Email: kucharz1980@interia.pl
}

\section{Mini Review \\ Volume 1 Issue 1}

Received Date: March 13, 2018

Published Date: March 26, 2018

DOI: $10.23880 /$ izab- 16000103

\section{Abstract}

This paper describes non-hymenoptera insects which are a potential source of allergens for sensitive people. Described species can also be a source of allergens to animals. It also presents the possibility of onset of cross-reactivity to allergens of insects and other organisms. It was pointed out the impact of climate change on the migration of insects.

Keywords: Allergy; Cross-Reactivity Reaction; Caterpillar; Fly; Butterfly

\section{Mini Review}

The current knowledge about the sources of allergens in the pathogenesis of various types of allergies as humans and animals must be verified. There are more and more new research methods using analysis of DNA, RNA, etc. Also, more and more new species of insects, plants, microorganisms are considered as potential " donor " allergens. Extracts of allergens are used in immunotherapy. After elimination from the environment of the allergen, the body recovers to health. Allergies are characterized by often very different clinical picture often difficult to diagnose. Besides allergens Hymenoptera, There are reports about the impact of allergens derived from insects non hymenoptera on the pathogenesis of allergies.

This applies to insects inhabiting near human settlements and is not limited to this fact only to rural areas. More and more new species of insects successfully dwell next to the man in the cities. They use other animals, the wind to spread and colonize new unknown regions. But also tourists returning from the tropics can bring on themselves or a new species of pathogens unknown with us and causing a variety of clinical symptoms, also schlep alien species on Polish territory from other continents has an impact on the " source of donors allergens [1].

Harmonia axyridis of the first reports on Polish territory appeared in the autumn of 2006. These insects migrate to human dwellings to survive the winter. In this species, said two allergens Hara 1 and Hara 2. Clinical allergy symptoms by the action of the allergen ladybirds manifested in conjunctivitis, asthma, urticaria, swelling etc [2].

Insect commonly found near the man's Musca domestica is a cosmopolitan insect. It exists in the vicinity of human settlements, and more. In buildings human survives the winter can anabiozy. It is a vector of many pathogens, parasites, viruses, etc. Allergies in humans are rare. Long time exposure to allergens housefly promotes the development of allergies [3-5]. Described the occurrence of cross-reactivity between allergens housefly and cockroach allergens in humans. Probably responsible for this is tropomyosin which also plays a role in triggering cross-reactions with Ascaris lumbricoides and Anisakis simplex [6].

Blue bottle fly (Calliphora Vomittoria): species whose larvae are used as fishing bait. Allergens released 


\section{International Journal of Zoology and Animal Biology}

from the fly larvae may be responsible for causing contact dermatitis. Describes a delayed asthmatic reaction, associated with human IgG $[6,7,3]$.

Greater wax moth Gallery melonella insect dwelling on patches of bee stored in improper conditions. Larvae are used as fishing bait.

Allergens contained in the hemolymph in susceptible people or constantly exposed to them $\mathrm{m}$. In: fishermen, breeders fishing lures can cause allergic reactions. The use of heat treatment, avoid this type of allergy without harming the amateur catch fish [8].

Mayflies (Ephemera Vulgate, Ephemera guttulata): allergen is inhaled insect cuticle, along with fragments of dead insects wings (after mating flights).

Caddis flies: are insects that live close to water courses, etc. It was found that the current on the surface of the surface of insect wings, Italian, detach and are inhaled into the respiratory tract where they cause inflammation. The major allergen is erytrokmoryna about 13 weight 000 $\mathrm{kDa}$. Says Cross reactions to allergens oysters, mussels, crabs, insects, etc. Although there are different opinions on this subject.

Aedesaegypti, Culexpipiens: females puncture the skin of a mammal, bird or reptile to download the camera gębowym blood needed to produce eggs. Male mosquitoes feed on nectar plants. Sting, is introduced saliva which contains a number of different substances that modulate the host organism are: anticoagulants, substances that facilitate the transmission of parasites, lysozyme, immunomodulators like. It has been found in the saliva of the mosquito allergens Aed a 1,2,3,4. Anaphylactic reactions are rare. Clinical symptoms after being bitten in susceptible individuals may persist for up to 24 hours [9]. In dogs observed hives, swelling vasomotor itching and anxiety, sometimes in forms of generalized may take the form of czyraczycy eosinophilic like. Because the mosquito after drinking the blood flies to lay their eggs, it is the owner of educating to your pet often controlling who and what around him" hums".

Symulinumargyreatum: are cosmopolitan insects. They dwell in the vicinity of damp. In Poland there are in the summer months. The saliva peptides are contained damaging tissue, anticoagulants, apyrase (allergen). Mouthparts in females causes tearing of the skin and anchor in it with the hook bent hairs. After the cessation of blood collection from the wound filtered blood. Itching leads to the infection of this place (scratching) by pathogens. It was found cross-reactions to the proteins contained in the saliva of mosquitoes and bugs and allergens saliva nap.

Drosofila melanogaster: commonly occurring, especially in the summer months. They encountered the most mature fruit which feeds and lays eggs. Stated in her allergen Dro $7 \mathrm{~m}$ (tropomyosin) showed cross reactions with proteins cockroaches and mites.

Cockroaches we include them species such as eastern cockroach Blattaorientalis and Blattellagermanica etc. They are cosmopolitan insects. The source of allergens is their feces. But virtually every part of the body of this insect can be a source of allergens. U cockroach stands out Bla g 1-7. Cockroach allergens are glycosylated proteins, a multimeric structure. Are enzymes, hormones etc. occur in the body of the insects.

These Include allergens showing cross-reactions Bla g 1, homologs hemocjanines, insect lipocalins (Bla g 4) homolog, glutathione transferase, homologs of the proteins involved in muscle contraction, or arginine kinase, a serine protease. Allergens can be specific to a particular species or may be similar to the allergens present in other organisms, eg. House dust mites, shrimp, bees etc. Allergies caused by these insects (their allergens) are one of the more common allergies in children. Which in combination with the situation of the family (parents atopic) makes that very easy there is sensitization to these allergens in young children under 4 years of age $[10,11]$.

Cimex lectularius: dwelling in the vicinity of human settlements. This insect is very durable for long periods without food which in this case is blood. Currently, the number of cases of bed bugs living in residential homes is increasing. In place of feeding appears itching, hives, pimples. The saliva are included substances which are irritating to the skin, which affect the production of cytokines, chemokines and these worse and support the inflammatory process in the skin (IL-8, GM-CSF, eotaxin). Interestingly contained in the hemolymph compounds do not exhibit such allergenic as those contained in the saliva of the bedbugs $[12,13]$.

Ctenocephalides canis, Ctenocephalides Felis, Pulex Irritans: They are cosmopolitan insects. They feed on the blood of the host by introducing substances into the bloodstream anticoagulants and on the other hand, in saliva allergens. Fleas dwell on the host during feeding and life cycle takes place outside the host. These insects also have the option of feeding on rodents, foxes, etc. 
Fleas are responsible for calling the strategy for flea allergy dermatitis (FAD). Nasilenei clinical symptoms does not depend on the size of flea infestation, but IgG and IgE antibodies against allergens contained in flea saliva (Cte $\mathrm{f} 1$, Cte $\mathrm{f} 2$ ). The flea saliva found so, which, upon a hapten of the skin collagen becomes the actual allergen [13].

Ixodes sp: Sometimes observed redness around screwed tick in the skin. It produced a small, red lump after a few days in a healthy individual disappears. When the dog finds immediate hypersensitivity reactions, but they rarely result in death of the animal.

Due to the fact that these insects dwell near human habitations, pets interact with them so they can also be exposed to allergens. In addition to these species of flies also worth mentioning species such as: Chrysops sp and Tabanus sp: (fly horse) their stings are painful [14] Accompanied by redness, swelling, hives. In place of this form scabs, sores. The most vulnerable are especially head and ears. Observed swelling of the eyes and lips. In humans rarely anaphylactic reactions. But said IgEmediated reactions to insect bites family Tabanus sp., And cross-reactions to allergens between species such as Stomoxyscalcitrans (Buzz Killer), and insects of the family Tabanus sp. These insects are also known vector of various diseases [15]. In man describes the case of crossreactivity to allergens contained in the venom of wasps bite of an insect of the family Tabanus sp [16].

Chrysops caecutiens: insect up to $10 \mathrm{~mm}$. females feed on mammals drinking their blood needed to produce eggs. Both adult males and females may feed on nectar and pollen Pyrethrum common (Leucantheum vulgare). The bites are painful and disturb the animals. Accompanied by itching, entanglements arising wounds after being bitten by pathogens.

Stomoxys Calcitrans: cosmopolitan species of flies. The size of about 6-7 mm, is similar to the housefly. Males and females feed on blood. Their bites are painful. In dairy cattle invasion of this species gives rise to anemia, weight loss, anxiety. As a result, the invasion of this species on the dog is observed necrotizing dermatitis at the ends of the ears, it is caused by allergens contained operating irritating to the host [17].

Thaumatopea Pityocampa: larvae are covered with numerous hairs. During contact with the hairs they dig into the skin or mucosa, eg. Nasal cavity etc., Encompassing a variety of substances (approx. 70) m. Al. taumetopoeine which has the capacity to release histamine from mast cells. The proteins contained in the hairs, are able to induce the expression of IL-4 and IL-13 to promote the development of eosinophils and basophils leading to increased inflammatory reaction. At the species T. pinivora Italian body larvae can remain in the skin for three weeks exacerbating allergic reaction $[18,19]$. Clinical symptoms usually localized to the facial part of the head, swelling around the eyes, lips. Rhinitis, or in extreme cases, anaphylactic shock. This species is found in southern Europe, the Middle East, Libya, in the Mediterranean. It exists at Pine Tree, Cedrus sp, larch. Caterpillars form clusters surrounded by a cocoon. These are listed a few of the insects that feed on blood and saliva from the introductory to the host organism allergens. Other insects because of staying close to the man, his offices are also a potential source of allergens often still undiscovered.

Butterfly caterpillars, especially covered with hairs, bristles, or spines forming their weapons in the fight against the threat are not without effect on allergic reactions in sensitive individuals. Said 'Korowódka' Mediterranean, is only an example of an insect that close contact can have dangerous consequences [20]. Climate change causes the appearance of alien species to native fauna. This applies not only to insects but also a whole series of different organisms. You should also get to know the flora and fauna of vegetable clusters in particular where we walk with the dog on walks - shafts, areas near bodies of water, meadows, etc. Studying the atlas of plants and animals. To be able to predict with which the inhabitants of our dog may have to deal with.

\section{References}

1. Sootkung N, Chaicumpa W (2010) A revisit this cocroach allergens. Asian Pac J Allergy Immunol 28(23): 95-106.

2. Goetz DW (2008) Harmonia axyridis ladybug invasion and allergy. Allergy Asthma Proc 29(2): 123129.

3. Tas E, Jappe U, Beltraminelli H, Bircher A (2007) Occupation Inhalant allergy to the common house fly (Musca domestica). Hautarzt. 58(2): 156-160.

4. Focke M, Hemmer W, Wohrl S, Gotz M, Jarisch R (2003) specific Sensitization is the common house fly (Musca domestica) not related to insect panallergy. Allergy 58(5): 448-451. 


\section{International Journal of Zoology and Animal Biology}

5. Villalta D, Martelli P, Mistrello G, Roncarolo D, Zanoni D (2004) bee moth (Gallery melonella) allergic reactions are Caused by several thermolabile antigens. Allergy 59(9): 1002-1005.

6. Scott JG, Warren WC, Beukeboom LW, Bopp D, Clark $A G$, et al. (2014) Genome of the house fly Musca domestica a global vector of diseases with Adaptations to a septic enviroment. Genome Biology 15(10): 466.

7. Carreño SP, de la Losa FP, Carrión EF, Martín ER, Cantariño AR, et al. (2009) Prothophormia terraenovae a new allergenic species in amateur fishermen of Caceres, Spain. Allergol Immunopathol 37(2): 68-72.

8. Rapiejko P, Agnieszka Lipiec (2006) Mosquitoes not only allergy. Alergoprofil 2: 21-25.

9. Żarski $T$ (2012) infectious diseases of the skin and subcutaneous tissue as a problem in people returning from travel abroad. Scientific Papers WSKFiT: 7.

10. Pomes A, Arruda LK (2014) Investigating cockroach allergens: aiming to improve diagnosis and treatment of cockroach allergic patient. Methods 66(1): 75-85.

11. Reinhard K (2009) Sensitivity to bites by the bed bug Cimexlectularius. Medical and Veterinary Entomology 23(2): 163-166.

12. Gaddart J, deShazo R (2009) Bedbugs (Cimexlectularius) and clinical consequnces of their bites. JAMA 301(13): 1358-1366.
13. Dobler G, Pfeffer M (2011) Fleas as parasites of the family Canidae. Parasites and Vectors 18(4): 139.

14. Baldacchino F, Muenworn V, Desquesnes M, Desoli F, Charoenviriyaphap $T$ (2013) Transmission of Pathogens by Stomoxys flies (Diptera, Muscidae): a review. Parasite 20(1): 26.

15. Bonamonte D (2013) Skin reactions to pine processionary caterpillar thaumetopoea pityocampa Schiff. The Scientific World Journal 2013: 6.

16. Pabis K (2013) Butterflies harmful to human health. KOSMOS-Problems of Biological Sciences tom 62(1): 47-60.

17. Hoffman DR (1987) Allergy a biting insects. Clinical reviews in allergy 5(2): 177-190

18. Vega J (2011) Skin Reactions on Exposure to the Pine Processionary Caterpillar (Thaumetopoea pityocampa). ACTA Dermo-Sifiligraficans 102(9): 658-667.

19. Quercia 0, Emiliani F, Foschi FG, Stefanini GF (2009) A Case of Anaphylaxis: Horse-fly or Hymenoptera stings. Eur Ann Allergy Clin Immunol 41(5): 152-154.

20. Porcel Carreño SL, Pineda de la Losa F, Frontera Carrión EM, Sanchez Gonzalez AB, Rodríguez Martín E, et al. (2013) Allergen Profile of Protophormiaterraenovae, and other species of Calliphoridae, and Lumbricusterrestris in anglers allergic to Maggots in Caceres, Spain. J Investig Allergol ClinImmunol 23(3): 176-182. 